\title{
Loss of PINK1 Function Affects Development and Results in Neurodegeneration in Zebrafish
}

\author{
Oleg Anichtchik, ${ }^{1}$ Heike Diekmann, ${ }^{1}$ Angeleen Fleming, ${ }^{1}$ Alan Roach, ${ }^{1}$ Paul Goldsmith, ${ }^{1,2}$ and David C. Rubinsztein ${ }^{3}$ \\ ${ }^{1}$ Summit, Waterbeach, Cambridge CB25 9TN, United Kingdom, ${ }^{2}$ Department of Neurology, Addenbrooke's Hospital, Cambridge CB2 2QQ, United \\ Kingdom, and ${ }^{3}$ Department of Medical Genetics, Cambridge Institute for Medical Research, Addenbrooke's Hospital, Cambridge CB2 2XY, United \\ Kingdom
}

\begin{abstract}
Parkinson's disease (PD) is the second most prevalent neurodegenerative disorder in the Western world. PTEN (phosphatase/tensin homolog on chromosome 10)-induced putative kinase 1 (PINK1), a putative kinase that is mutated in autosomal recessive forms of PD, is also implicated in sporadic cases of the disease. Although the mutations appear to result in a loss of function, the roles of this protein and the pathways involved in PINK1 PD are poorly understood. Here, we generated a vertebrate model of PINK1 insufficiency using morpholino oligonucleotide knockdown in zebrafish (Danio rerio). PINK1 knockdown results in a severe developmental phenotype that is rescued by wild-type human PINK1 mRNA. Morphants display a moderate decrease in the numbers of central dopaminergic neurons and alterations of mitochondrial function, including increases in caspase-3 activity and reactive oxygen species (ROS) levels. When the morphants were exposed to several drugs with antioxidant properties, ROS levels were normalized and the associated phenotype improved. In addition, GSK3 $\beta$-related mechanisms can account for some of the effects of PINK1 knockdown, as morphant fish show elevated GSK3 $\beta$ activity and their phenotype is partially abrogated by GSK3 $\beta$ inhibitors, such as LiCl and SB216763 [3-(2,4dichlorophenyl)-4-(1-methyl-1H-indol-3-yl) $1 H$-pyrrole-2,5-dione]. This provides new insights into the biology of PINK1 and a possible therapeutic avenue for further investigation.
\end{abstract}

Key words: Parkinson's disease; zebrafish; neurodegeneration; mitochondria; ROS; PINK1

\section{Introduction}

Parkinson's disease (PD) is the second most prevalent neurodegenerative disorder in the Western world. To date six genes with pathogenic mutations have been identified as contributing to Mendelian forms of PD. These include two autosomal dominant genes, $\alpha$-synuclein $(S N C A)$ and leucine-rich repeat kinase 2 (LRRK2), and three autosomal recessive genes, parkin, DJ-1, and phosphatase/tensin homolog on chromosome 10 (PTEN)induced putative kinase 1 (PINK1) (Valente et al., 2004; Klein and Schlossmacher, 2006). An apparently dominant mutation in a sixth gene, ubiquitin C-terminal hydrolase L1 (UCHL1), has only been found in one small family and its relevance to familial PD is still debated (Healy et al., 2006). PINK1 mutations are the second most common cause of autosomal recessive PD after par-

Received Nov. 16, 2007; revised July 1, 2008; accepted July 4, 2008.

This work was supported by the Medical Research Council and the Department of Trade and Industry. D.C.R. is a Wellcome Trust Senior Research Fellow in Clinical Science. We acknowledge the Summit (Cambridge) aquarium staff for support and maintenance of the fish facility.

H.D., A.F., and A.R. are employees of Summit plc and have share options in this company. A.F., P.G., and A.R. are shareholders in Summit plc.

Correspondence should be addressed to either of the following: Oleg Anichtchik at his present address, Cambridge Centre for Brain Repair/Department of Clinical Neuroscience, E. D. Adrian Building, Forvie Site, Robinson Way, Cambridge CB2 OPY, UK, E-mail: 0a220@cam.ac.uk; or David C. Rubinsztein, Department of Medical Genetics, Cambridge Institute for Medical Research, Wellcome/MRC Building, Addenbrooke's Hospital, Hills Road, Cambridge CB2 2XY UK, E-mail: dcr1000@hermes.cam.ac.uk.

P. Goldsmith's present address: Department of Neurology, Royal Victoria Infirmary, Queen Victoria Road, Newcastle upon Tyne NE1 4LP, UK.

DOI:10.1523/JNEUROSCI.0979-08.2008

Copyright $\odot 2008$ Society for Neuroscience $\quad$ 0270-6474/08/288199-09\$15.00/0 kin (Li et al., 2005), and PINK1 is also implicated in sporadic cases of the disease (Valente et al., 2004). PINK1 is a highly conserved 581 aa protein that is widely expressed in the human brain and localizes to mitochondrial membranes via an N-terminal targeting motif (Gandhi et al., 2006). It shares homology with calmodulin-dependent protein kinase 1, contains a catalytic serine-threonine kinase domain, and has autophosphorylation activity in vitro (Sim et al., 2006). PD-causing mutations appear to result in loss of function (Sim et al., 2006).

Recent studies of PINK1 in Drosophila melanogaster suggest its importance for mitochondrial function. Loss-of-function mutants of PINK1 exhibit male sterility, muscle and dopaminergic neuron degeneration, and increased sensitivity to stressors (Clark et al., 2006; Park et al., 2006; Yang et al., 2006). PINK1 mutant flies have decreased expression of parkin and have phenotypes similar to flies with loss of parkin function. Because overexpression of parkin rescues phenotypes caused by PINK1 deficiency, but not vice versa, it has been proposed that parkin acts downstream of PINK1, also suggesting that understanding PINK1 function may be relevant for PD caused by either parkin or PINK1 mutations. The molecular targets of PINK1 kinase activity are poorly studied. Recently, the phosphorylation of mitochondrial molecular chaperone TRAP1 was attributed to PINK1 (Pridgeon et al., 2007), further strengthening the mitochondrial relevance of PINK1.

\section{Materials and Methods}

Zebrafish strain husbandry and in situ hybridization. Wild-type zebrafish of the $\mathrm{AB}$ strain were maintained at $28.5^{\circ} \mathrm{C}$ under standard conditions 
(Westerfield, 2000) in compliance with Animal Welfare legislation. Embryos were collected after natural spawning, staged as described previously (Kimmel et al., 1995), and raised in embryo medium (Westerfield, 2000). Whole-mount in situ hybridization was done as described previously (Jowett and Lettice, 1994). Antisense digoxigenin-labeled RNA probes were generated using cDNAs of pink1, parkin, reelin (Costagli et al., 2002), fezl (Levkowitz et al., 2003), and neurogenin-1 (ngn-1) (Blader et al., 1997). All husbandry and experimental procedures were performed in accordance with the Animals (Scientific Procedures) Act.

In silico identification of zebrafish PINK1 orthologue. To identify the zebrafish PINK1 orthologue, a basic local alignment search tool (BLAST) search of the Ensembl zebrafish cDNA database (http://www.ensembl. org/Danio_rerio/index.html) was performed using the human PINK1 amino acid sequence (ENSG00000158828). Based on the obtained sequences, primers were designed to amplify the complete sequence of the zebrafish gene. mRNA, isolated from different age embryos, was reverse transcribed with the First-Strand Synthesis Kit (Invitrogen). PCR products were analyzed by agarose gel electrophoresis and sequenced.

Morpholino and mRNA injections and drug treatment. Morpholino oligonucleotides (MOs) (ATG targeting, 5'-GCT GAG AAC ATG CTT TAC TGA CAT T-3'; $5^{\prime}$-untranslated region (UTR) targeting, 5' -ATA TTG ACT ATG AGA GGA AAT CTG A-3'; ATG-targeting five-mispair control, 5'-GCT CAC AAC ATC CTT TAG TGA GAT T-3'; 5'-UTR targeting five-mispair control, $5^{\prime}$-ATA TTC AGT ATC AGA GCA AAT GTG A-3') targeting either the ATG or 5'-UTR region of the zebrafish PINK1 gene were obtained from Gene Tools and dissolved in $1 \times$ Danieau medium [containing (in $\mathrm{mm}$ ) $58 \mathrm{NaCl}, 0.7 \mathrm{KCl}, 0.4 \mathrm{MgSO}_{4}, 0.6$ $\mathrm{Ca}\left(\mathrm{NO}_{3}\right), 2.5$ HEPES, pH 7.6]. One-cell stage embryos were injected with a combination of ATG and 5'-UTR morpholinos at 7, 9, and 13 ng each. Five-mispair control morpholinos were used to determine the concentrations of injected morpholino that produced phenotypes that were disctinct from morpholino toxicity. Additional controls to monitor the quality of the injection technique included injections of a standard control morpholino ( $5^{\prime}$-CCT CTT ACC TCA GTT ACA ATT TAT A- $\left.3^{\prime}\right)$, which targets a splice site in the human $\beta$-globin gene (negative control), and a morpholino targeting the zebrafish chordin gene (5'-ATC CAC AGC AGC CCC TCC ATC ATC C-3') (positive control) (all from Gene Tools).

Capped mRNAs were synthesized from cDNAs cloned into pcDNA/ V5-DEST, encoding human full-length wild-type PINK1 gene using the T7 mMessage mMachine kit (Ambion). Sites corresponding to the clinically relevant mutations A168P and W347X were altered using the QuikChange II XL Site-Directed Mutagenesis Kit (Stratagene). Sixty-five picograms of mRNA were coinjected together with PINK1 MOs into embryos at the one-cell stage.

For the pharmacological rescue experiments, $\mathrm{LiCl}$ (0.5-50 mm; SigmaAldrich), 3-(2,4-dichlorophenyl)-4-(1-methyl-1 H-indol-3-yl) $1 H$-pyrrole2,5-dione (SB216763; 1-10 $\mu \mathrm{M}$; Tocris Bioscience), reduced glutathione $(\mathrm{GSH} ; 100 \mu \mathrm{M})$ and $N$-acetyl-cysteine (NAC; $100 \mu \mathrm{M})$ were dissolved in DMSO or water and were introduced into the embryonic media $6 \mathrm{~h}$ after morpholino injection The final concentration of DMSO was $0.2 \%$ in the water. Fish were analyzed 24 and $48 \mathrm{~h}$ after injection.

For quantification of the rescue results, data were gathered from 15-20 embryos at each stage and age. The normal phenotype was expressed as $100 \%$, and the changes in the morphology were scored and calculated accordingly. Data from at least three experiments were pooled for statistical analyses.

We used five-mispair control MOs as the "control state" in the present study unless indicated otherwise. Generally, five-mispair control MO at the concentration used did not produce any phenotype different from naive fish.

Immunohistochemistry and PAGE. Immunohistochemistry for acetylated tubulin (Sigma-Aldrich), tyrosine-hydroxylase, serotonin (5-HT) (Immunostar), and PINK1 (Cayman Chemicals) was performed as described previously (Kaslin and Panula, 2001). Images were taken using an Olympus SZX12 or BX51 fluorescence microscope equipped with digital camera, and processed using AnalySIS ${ }^{\mathrm{D}} 5.0$ software (Soft Imaging System). No adjustment of brightness or contrast was made after image acquisition. For Western blotting, embryos of $24-48 \mathrm{~h}$ postfertilization (hpf) were dechorionated, deyolked (Link et al., 2006), homogenated in radioimmunoprecipitation assay (RIPA) buffer with protease and phosphatase inhibitors, and processed for SDS-PAGE. Immunoreactive bands were detected with ECL reagent (GE Healthcare Life Sciences) and chemiluminescent signal was visualized by the exposing membrane to ECL Hyperfilm (GE Healthcare Life Sciences). Films were scanned using a desktop scanner HP ScanJet 3800, and densitometric analysis of blots was performed using ImageJ software (National Institutes of Health). The background intensity of the film was subtracted from the band intensity. At least three separate experiments were analyzed, and band intensities were normalized to the loading control band intensity. Quantification of tyrosine hydroxylase (TH)-positive neurons was done in 24 and 48 hpf whole-mount, deyolked, flat-mounted embryos by counting all fluorescent cell bodies in the brain using a $40 \times$ objective. The number of neurons in control five-mispair MO-injected embryos was presented as $100 \%$, and the changes in the PINK1 MO group was calculated accordingly. Each experiment analyzed at least seven embryos in each group, and data from at least four experiments were pooled for the statistical analyses.

Detection of cell death. Apoptotic/necrotic cells were detected by incubation of live 24- to 48-hpf-old embryos in acridine orange solution (5 $\mu \mathrm{g} / \mathrm{ml}$ ) (Furutani-Seiki et al., 1996). Cells loaded with the dye were visualized using a tetramethylrhodamine isothiocyanate filter on the Olympus SZX12 fluorescent microscope. To detect the activity of caspase-3 in zebrafish embryos, fish were homogenated in ice-cold RIPA buffer and the homogenate was mixed with an equal volume of $0.39 \mathrm{~mm}$ acetyl Asp-Glu-Val-Asp 7-amido-4-methylcoumarin (Sigma-Aldrich), a selective caspase-3 substrate, resulting in the release of the fluorescent 7-amino-4-methylcoumarin (AMC). The excitation and emission wavelengths of AMC (360 and $460 \mathrm{~nm}$, respectively) were detected using a Victor $^{3}$ plate reader (PerkinElmer Life And Analytical Sciences). The reactions were normalized with total protein concentrations. Embryos treated with UV light $\left(400 \mu \mathrm{J} / \mathrm{cm}^{2}, 0.1 \mathrm{~s}\right)$ for $6 \mathrm{~h}$ before the assay served as a positive control of apoptosis-induced caspase-3 activation. Incubation with $100 \mu \mathrm{M}$ pan-caspase-3 inhibitor benzyloxycarbonyl-Val-AlaAsp (OMe)-fluoromethylketone (zVAD; R\&D Systems) was used as a negative control.

Reactive oxygen species (ROS) accumulation, assessed by the levels of the oxidized form of the cell-permeant ROS indicator acetyl ester of 5-(and 6-)chloromethyl-2',7'-dichlorodihydrofluorescein diacetate (CM- $\mathrm{H}_{2}$ DCFDA) (Invitrogen), was detected in live fish as follows. Injected embryos were dechorionated, several groups of three embryos were put in the wells of a 96-well plate, and excess medium was removed using a fire-polished glass Pasteur pipette. Embryos were incubated in 1 $\mu \mathrm{g} / \mathrm{ml} \mathrm{CM}-\mathrm{H}_{2}$ DCFDA for up to $2 \mathrm{~h}$, and the fluorescence was measured with a Victor ${ }^{3}$ plate reader (PerkinElmer Life And Analytical Sciences) (excitation $485 \mathrm{~nm}$, emission $560 \mathrm{~nm}$ ) after every $10 \mathrm{~min}$. The spontaneous oxidation of CM- $\mathrm{H}_{2}$ DCFDA was monitored in the wells without fish, and the levels were low and did not change with time. $\mathrm{H}_{2} \mathrm{O}_{2}$ solution served as a positive control.

Isolation of mitochondria. Crude mitochondrial and cytoplasmic fractions were isolated using a Mitoiso 1 isolation kit (Sigma-Aldrich). Briefly, embryos 80-100 24 hpf were collected, dechorionated, and homogenated in the supplied extraction buffer (10 mM HEPES buffer, $\mathrm{pH}$ 7.5, containing $200 \mathrm{~mm}$ mannitol, $70 \mathrm{~mm}$ sucrose, $1 \mathrm{~mm}$ EGTA, and 2 $\mathrm{mg} / \mathrm{ml} \mathrm{BSA}$ ). Homogenates were spun at $600 \times g$ in $4^{\circ} \mathrm{C}$, and supernatants were then spun at $11,000 \times g$ for $10 \mathrm{~min}$ in $4^{\circ} \mathrm{C}$. Supernatants, representing cytoplasmic fractions, were removed and stored in ice. Pellets were resuspended in extraction buffer, and the centrifugations were repeated. The resulting pellets were resuspended in storage buffer $[10 \mathrm{mM}$ HEPES buffer, $\mathrm{pH} 7.5$, containing (in mM) 250 sucrose, 1 ATP, 0.08 ADP, 5 sodium succinate, $2 \mathrm{~K}_{2} \mathrm{HPO}_{4}$, and $1 \mathrm{DTT}$ ], and the protein concentration was assayed using the Bradford method. 5,5',6,6'-Tetracloro$1,1^{\prime}, 3,3^{\prime}$-tetraethylbenzimidazolcarbocyanine iodide (JC-1) uptake, an indicator of mitochondrial $\Delta \psi$ membrane potential, was then assessed by incubation adjusted by protein levels. The preparations were incubated for $10 \mathrm{~min}$ in the dark, and fluorescence was detected using a Victor ${ }^{3}$ plate reader (PerkinElmer Life and Analytical Sciences) (excitation, 490 $\mathrm{nm}$; emission, 525 and $590 \mathrm{~nm}$ ). The ratio of 590/530 nm (orange/green) 
$\mathbf{A}$

Pink1

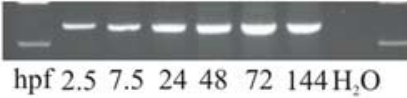

B

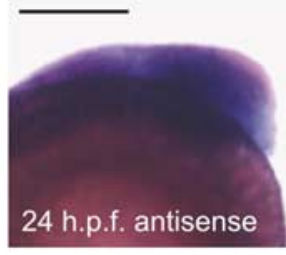

C
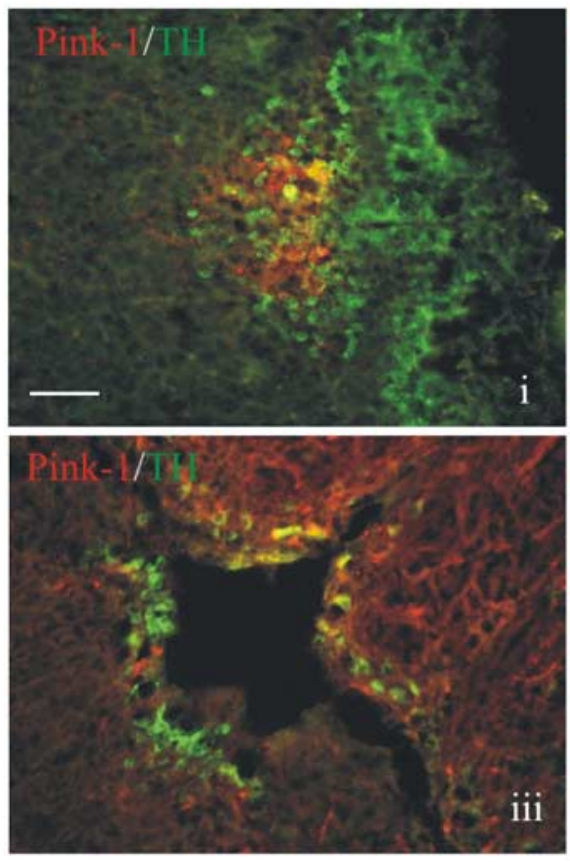
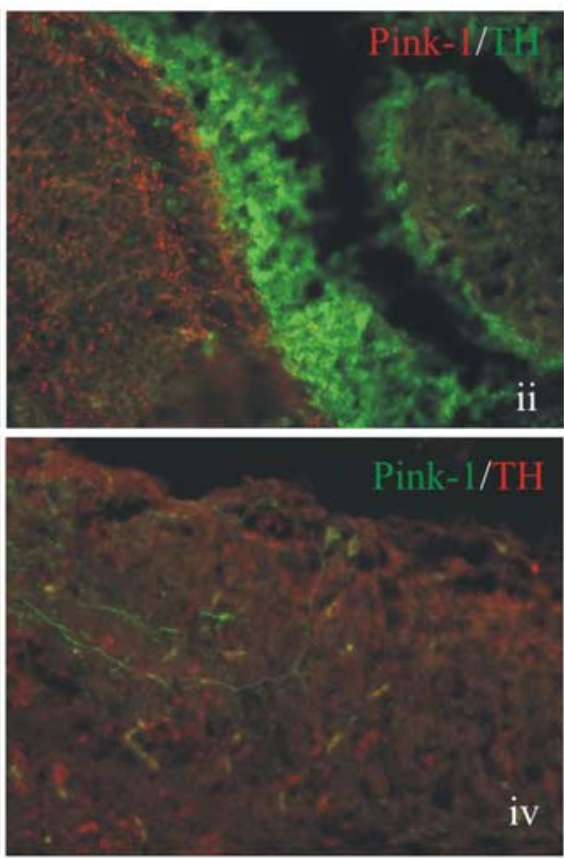
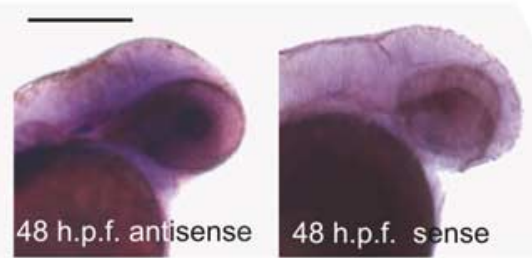

48 h.p.f. sense

$\mathbf{E}$
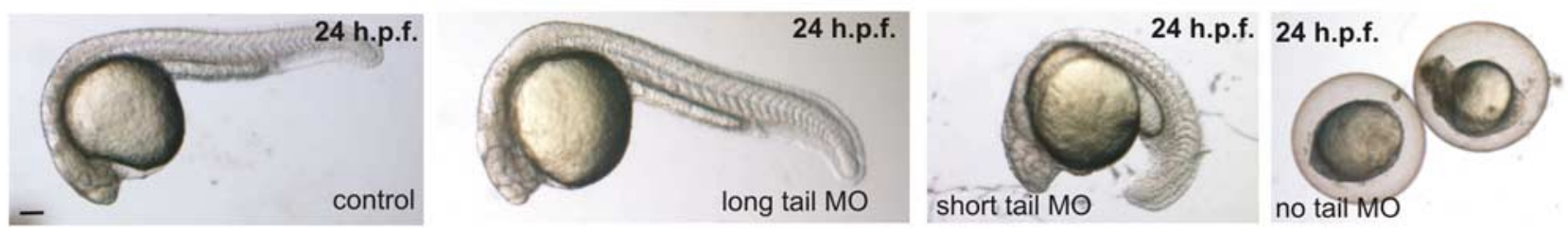

F
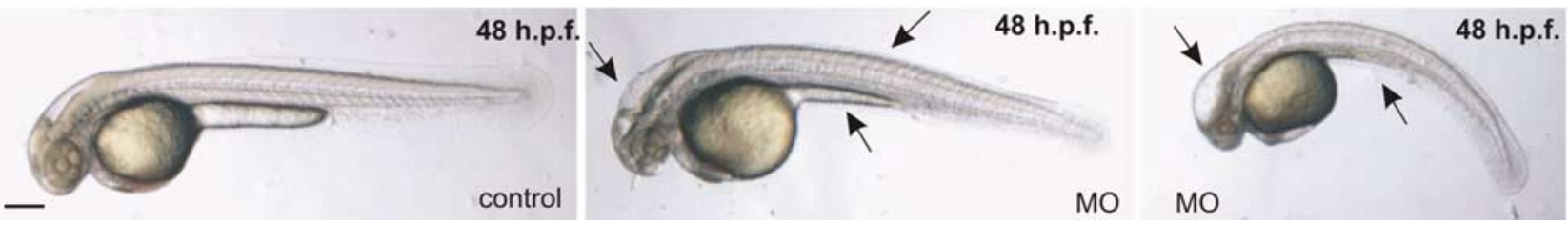

Figure 1. Characterization of zebrafish PINK1. A, RT-PCR analysis of PINK1 mRNA expression at different hours after fertilization. B, In situ hybridization showing expression of zebrafish PINK1 mRNA in 24 and 48 hpf embryos. Right, Negative control staining with sense probe. C, Immunohistochemical analysis of PINK1 protein (green) and TH (red) in adult zebrafish brain (i-iii). PINK1 protein is localized ubiquitously with the tendency to be enriched along ventricular surfaces. In some areas (hypothalamus), PINK1 protein is colocalized with tyrosine hydroxylase. $\boldsymbol{i}$, Posterior hypothalamus; ii, optic tectum; iii, areas around diencephalic ventricle; iv, posterior tuberculum (PINK1 protein, red; TH, green). D, The PINK1 antibody used (Cayman Chemicals, catalog \#10006283) detects bands of $\sim 66$ and $\sim 33 \mathrm{kDa}$ in mouse liver mitochondria preparations. Similarly sized bands are seen in the wild-type zebrafish, and these disappear in PINK1 M0-treated fish. The trend in this gel is representative of at least five replicate experiments. E, PINK1 morphants at $24 \mathrm{hpf}$ after injection of $7 \mathrm{ng}$ of MOs show long-tail, short-tail, and no-tail phenotypes. Five-mismatch M0 control zebrafish look the same as uninjected siblings. $\boldsymbol{F}$, Phenotype of PINK1 morphants at $48 \mathrm{hpf}$ after injection of $7 \mathrm{ng}$ of MO. Enlarged brain ventricle, slim tail-yolk extension, and curved spines are indicated by arrows in mildly (middle) and severely (right) affected morphants. Scale bars: $\boldsymbol{B}, \boldsymbol{E}, \boldsymbol{F}, 100 \mu \mathrm{m} ; \boldsymbol{C}, 50 \mu \mathrm{m}$.

was considered as an indicator of mitochondrial $\Delta \psi$ membrane potential. Incubation with $1 \mu \mathrm{g} / \mathrm{ml}$ valinomycin resulted in decrease of JC-1 orange/green fluorescence, and was used as a positive control. The purity of the resulting preparation was assessed, using actin as a control for cytoplasm, and porin as a mitochondrial loading control (supplemental Fig. 1, available at www.jneurosci.org as supplemental material).

Statistics. Pooled estimates for the changes in tail phenotype, resulting from perturbations assessed in multiple experiments, were calculated as 

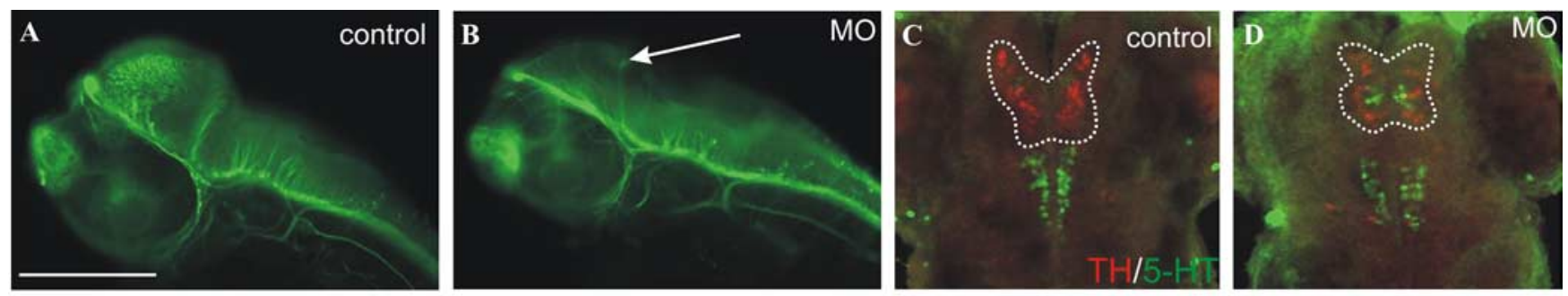

E
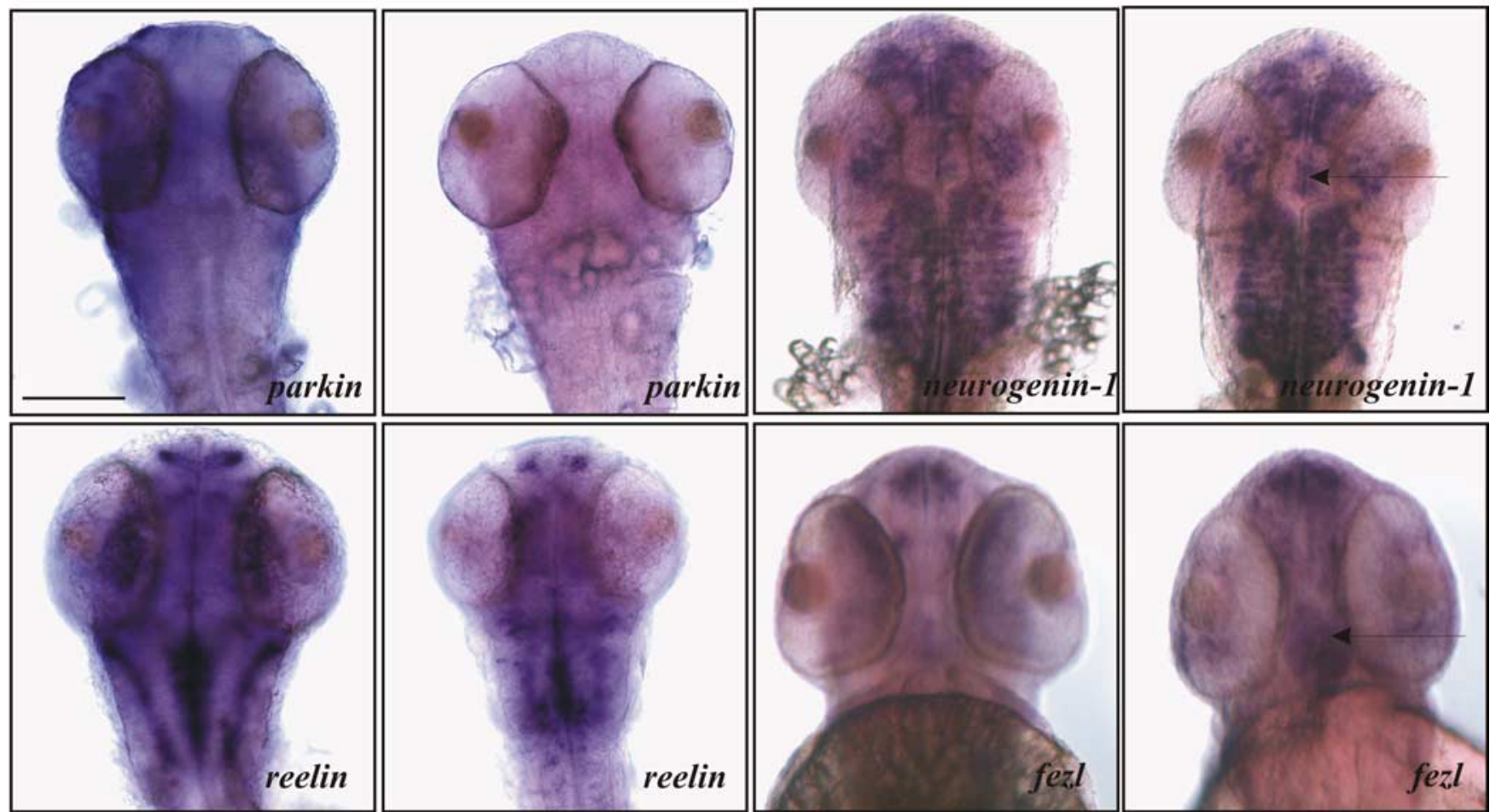

control

PINK1 MO

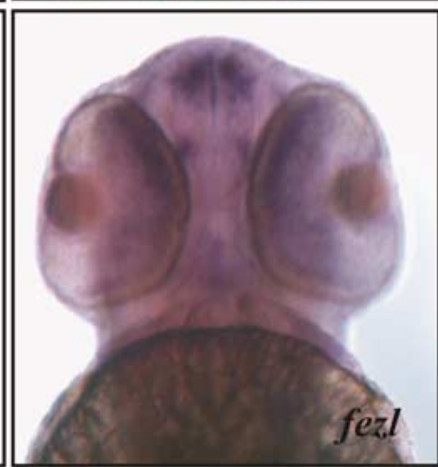

control

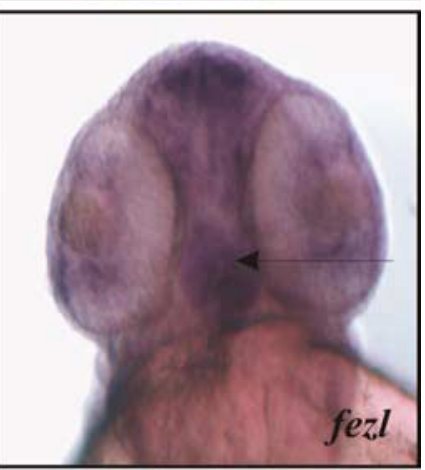

PINK1 MO
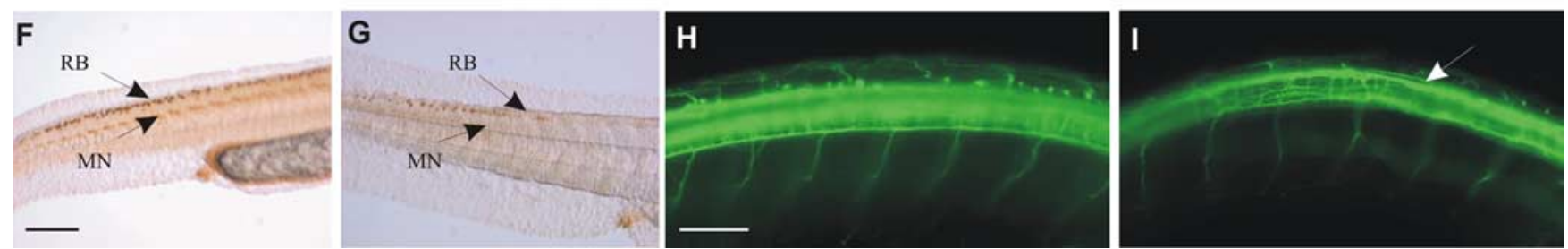

Figure 2. Morphological characterization of PINK1-deficient fish. $\boldsymbol{A}, \boldsymbol{B}$, Acetylated tubulin immunostaining in M0-injected ( $\boldsymbol{A}$ ) and five-mispair M0 control ( $\boldsymbol{B})$ embryos at 48 hpf. The decrease in staining in the tectal area is indicated by an arrow. $\boldsymbol{C}, \boldsymbol{D}$, TH and 5-HT staining in representative M0-injected ( $\boldsymbol{C}$ ) and five-mispair M0 control (D) embryos at $48 \mathrm{dpf}$. The diencephalic cluster of dopaminergic cells is outlined. $\boldsymbol{E}$, In situ hybridization of PINK1 MO-injected and control embryos at 48 hpf. The increase in fezl and ngn-1 expression in morphants is indicated by arrows. $\boldsymbol{F}, \boldsymbol{G}$, Immunohistochemistry with antibody $40.2 \mathrm{D} 6$ (islet-1) in the trunk of control $(\boldsymbol{F})$ and M0-injected (G) fish, showing decreased staining in M0 fish. $\boldsymbol{H}, \boldsymbol{I}$, Acetylated tubulin staining in the trunk of control $(\boldsymbol{H})$ and $\mathrm{MO}$-injected $(\boldsymbol{I})$ fish. Changes in the morphology (e.g., decrease in neuron numbers) of spinal neurons are indicated by arrows. RB, Sensory Rohon-Beard neuron; MN, primary motoneuron. Scale bars, $100 \mu \mathrm{m}$.

odds ratios with $95 \%$ confidence intervals. We used this method frequently in the past to allow analysis of data from multiple independent experiments (Wyttenbach et al., 2001, 2002; Carmichael et al., 2002). Odds ratios and $p$ values were determined by unconditional logistical regression analysis, using the general log-linear analysis option of SPSS 9 software. In other experiments, two-way ANOVA and $t$ test (GraphPad Prism 4) were used when applicable.

\section{Results}

Identification of zebrafish PINK1

Here, we inhibited translation of PINK1 in zebrafish with MOs to examine its roles in vertebrate development. To identify the ze- brafish gene, we performed BLAST searches with the human PINK1 protein sequence (NP_115785) in the Ensembl zebrafish database and identified putative zebrafish PINK1 transcripts, which were confirmed by PCR cloning. Zebrafish PINK1 (NM_001008628) encodes a 574 aa protein with a predicted molecular mass of $64 \mathrm{kDa}$ and is $54 \%$ identical to the human PINK1 protein (supplemental Fig. 2, available at www.jneurosci.org as supplemental material). Analysis of the zebrafish primary sequence revealed a putative mitochondrial targeting domain at the $\mathrm{N}$ terminus of the protein with a possible cleavage site at amino acid 88 (MitoProt) (Claros and Vincens, 1996) and a putative 
A

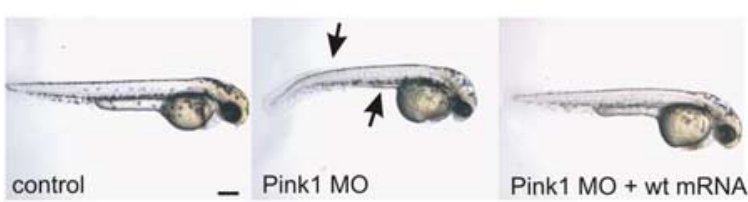

C
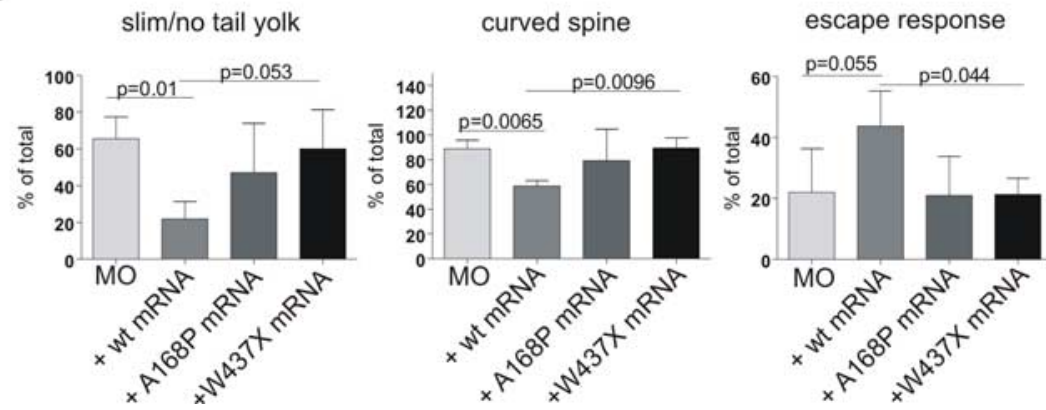

Figure 3. Rescue of PINK1 MO phenotype with full-length human PINK1 mRNA. $\boldsymbol{A}$, Rescue of the overall M0 phenotype at 48 hpf by coinjected full-length human PINK1 mRNA. The phenotypes assessed (curved back, small tail-yolk extension) are indicated with arrows. Scale bar, $100 \mu \mathrm{m}$. B, Coinjection of MOs with human full-length mRNA partially restores PINK1 levels in $24 \mathrm{hpf}$ embryos. C, Coinjection of mutant human mRNA did not produce a rescue of PINK1-deficient phenotype. The bars represent changes in the assessed phenotype relative to the $\mathrm{MO}$-induced phenotype in three independent experiments. Error bars indicate SEM.

Ser-Thr protein kinase active site at amino acids 346-358, which is highly similar to human PINK1 (supplemental Fig. 2, available at www.jneurosci.org as supplemental material).

Using RT-PCR, zebrafish PINK1 mRNA was detected as early as $2.5 \mathrm{hpf}$ and throughout development up to $144 \mathrm{hpf}$ (Fig. 1A). In situ hybridization detected PINK1 mRNA that was distributed fairly uniformly in zebrafish larvae at 24 and $48 \mathrm{hpf}$, with increased intensity in the nervous system and muscle (Fig. $1 B$ ). Polyclonal antibodies raised against human PINK1 peptide detected signals within the paraventricular regions of the adult zebrafish brain, including the hypothalamus and the deep layers of the optic tectum (Fig. 1C). In some areas (e.g., the hypothalamus), we observed overlapping signals for PINK1 and TH, suggesting the presence of PINK1 in some dopaminergic neurons. We detected two PINK1-positive bands in the whole zebrafish lysates: a smaller one, $\sim 33 \mathrm{kDa}$, and a larger one, $\sim 66 \mathrm{kDa}$. Injection of PINK1 MOs led to a dose-dependent decrease of the intensity of the PINK1 bands from 24 hpf fish (Fig. 1D). We observed these bands in both cytoplasmic and mitochondrial fractions of whole $24 \mathrm{hpf}$ embryos homogenates (supplemental Fig. 3, available at www.jneurosci.org as supplemental material). PINK1 bands approximating the size of the smaller fragment we observed in zebrafish have been reported recently in human cell lines (Lin and Kan, 2008).

\section{Phenotype of PINK1 knockdown}

To examine morphological changes caused by PINK1 deficiency, embryos were injected with MOs directed against the $5^{\prime}$-UTR and the ATG start codon of zebrafish PINK1 (7 ng of each ATG and UTR MO in combination). Using otherwise identical MOs with 5 bp substitutions (control MO), no morphological abnormalities were observed up to $6 \mathrm{~d}$ postfertilization (dpf). MOs that block zebrafish PINK1 translation did not affect gastrulation but resulted in three distinct phenotypic groups at $24 \mathrm{hpf}$ (Fig. $1 \mathrm{E}$ ). The first group had dark, nontransparent heads but properly developed trunks/tails ["long-tail" group, $13.8 \pm 2.71 \%$ (SD) of embryos]; the second group had dark, nontransparent heads, small eyes, and short, curved tails with misshapen somites ("short-tail" group, $79 \pm 3.5 \%$ of embryos); and the third group appeared to have halted head/ tail development ("no-tail" group, $6.6 \pm$ $2.8 \%$ of embryos). Injection of higher doses of MO (>10 ng) resulted in an increase in the size of no-tail group and disappearance of the long-tail group. At 48 hpf, the predominant phenotype (with 7 ng of MO) was in the trunk/tail: MOinjected fish had various degrees of ventral curvature of the spine with misshapen tail ends (Fig. $1 F$ ). In addition, they had enlarged brain ventricles, small heads, and slim yolk extensions and occasionally manifested cardiac edema. These embryos failed to swim away when touched on the tail (impaired escape response). By 72 hpf, the most severely affected larvae died, whereas surviving larvae showed some recovery. Note that the effects of MOs decrease with time after injection, with most activity being lost by $\sim 5 \mathrm{~d}$. In general, MO-induced translational inhibition is most efficient during the first 2-3 d of development (Sumanas and Larson, 2002).

Injection of PINK1 MO resulted in structural alterations in the axonal scaffold of the larval nervous system: commissures were less prominent, sometimes the tegmental commissure failed to develop and the paramedial descending axonal tract in the hindbrain and spinal cord were disorganized (Fig. $2 A, B$ ). The number of $\mathrm{TH}$-positive neurons in the diencephalon of MOinjected zebrafish at $48 \mathrm{hpf}$ was reduced to $62.7 \pm 6.05 \%$ SEM of control levels $100 \%$ ( $p=0.012 ; n=3)$, whereas serotoninergic (5-HT) neurons were not affected (Fig. 2C,D, supplemental Fig. 4, available at www.jneurosci.org as supplemental material). Several in situ hybridization probes were used to examine neuron development (Fig. 2E). Expression of reelin, a general neuronal marker (Costagli et al., 2002), was decreased in PINK1 morphants. In accordance with the Drosophila PINK1 knock-out data (Yang et al., 2006), parkin expression was also reduced in the brain of PINK1 morphants. However, fezl mRNA, one of the factors required for the development of the dopaminergic system in zebrafish, was selectively increased in the posterior diencephalon of PINK1 morphants. Neurogenin-1, a downstream target of fezl (Jeong et al., 2006), was similarly upregulated in PINK1 morphants (Fig. 2E). In the spinal cord, PINK1 morphants showed decreased islet- 1 and acetylated tubulin staining, suggesting loss of peripheral neurons (Abdelilah et al., 1996; Devine and Key, 2003) (Fig. 2F-I).

To test whether the zebrafish PINK1 knockdown phenotype was relevant to human PINK1 function, experiments were performed to ascertain whether the MO phenotype could be rescued by wild-type human PINK1 mRNA. mRNA (65 pg, which by itself did not cause an obvious external phenotype) was injected together with the MOs and the phenotype scored at $48 \mathrm{hpf}$ (Fig. $3 A$ ). The mRNA mostly rescued the PINK1 MO phenotype as 
changes of the shape of tail yolk, curvature of the spine/tail and loss of escape response were reversed. Although 71.7\% ( $\pm 6.6 \%$, SEM) of the MO treated fish had the slim tail yolk/no tail yolk phenotype, this was reduced to $35.8 \%$ ( $\pm 7.3 \%$, SEM; $p<0.001$; $n=6)$ with coinjection of the human PINK1 mRNA with the MO. Likewise, the curved spine phenotype in the MO fish $(82.4 \pm 6.3 \%)$ was improved to $41.8 \%( \pm 14.2 \%$, SEM; $p<0.001$; $n=4)$ by coinjection of the human PINK1 mRNA, and the escape response in the MO fish $(30.9 \pm 8.5 \%$, SEM) was improved to $55.3 \%$ ( $\pm 7.2 \%$, SEM; $p<0.001 ; n=7$ ) by coinjection of the human PINK1 mRNA. In addition, overexpression of human PINK1 mRNA partially restored decreased levels of PINK1 protein, confirming the specificity of the used antibodies (Fig. 3B, supplemental Fig. 5A, available at www.jneurosci.org as supplemental material). The injection of mRNA into five-mispair control MO-injected embryos at this concentration did not produce obvious changes in the normal phenotype.

Several mutations of PINK1 that alter its activity have been described in humans (Valente et al., 2004; Silvestri et al., 2005). We introduced two such mutations, A168P and W437X, into the human full-length PINK1 mRNA. These mutated mRNAs did not rescue the phenotypes observed with PINK1 MO in the same way that we observed with the wild-type PINK1 mRNA (Fig. 3C).

\section{PINK1 knockdown influences AKT-GSK3 $\beta$ axis}

The tail phenotype of PINK1 MO-injected zebrafish at $24 \mathrm{hpf}$ (short tail) looked remarkably similar to wnt pathway mutants (e.g., pipe-tail) (Rauch et al., 1997). Furthermore, fezl, the expression of which is upregulated in our PINK1 morphants, is also induced in zebrafish embryos expressing the wnt pathway inhibitor DKK1 (Hashimoto et al., 2000a). Accordingly, we hypothesized that PINK1 knockdown enhanced GSK $3 \beta$ activity (a consequence of wnt inhibition). Indeed, PINK1 morphants showed a decrease in the amount of inactive Serine 9 (Ser9)phosphorylated forms of GSK3 $\beta$ (Fig. $4 A$ ). Active GSK3 $\beta$ phosphorylates $\beta$-catenin, enhancing its degradation. Consistent with predictions, active $\beta$-catenin levels were decreased in PINK1 morphants (Fig. $4 B$ ).

To test whether enhanced GSK3 $\beta$ activity contributed to the phenotypes we observed in PINK1 morphants, we treated them with nonspecific ( $\mathrm{LiCl}$ ) and specific (SB216763) GSK-3 $\beta$ inhibitors. After performing preliminary concentration-response curves with $\mathrm{LiCl}$ (supplemental Fig. 5B, available at www. jneurosci.org as supplemental material), we used $50 \mathrm{~mm}$ for a series of independent replicate experiments. Both compounds were able to rescue $\sim 20 \%$ of short tail morphants at $24 \mathrm{hpf}$ (Fig. $4 C$ ). Moreover, treatment with $\mathrm{LiCl}$ partially restored decreased levels of active $\beta$-catenin in PINK1 MO embryos (Fig. 4D). However, both treatments failed to reverse the dark-head phenotype.

AKT is an important regulator of GSK3 $\beta$ activity as it phosphorylates GSK $3 \beta$ on serine 9, resulting in inhibition of the enzyme. AKT activity, assessed by the amounts of its phosphorylated serine 473 form, was decreased in whole lysates of $24 \mathrm{hpf}$ PINK1 morphants (Fig. 4 E). As expected, LiCl, which rescued tail phenotype of PINK1 morphants and restored Ser9 GSK3 $\beta$ levels, did not affect decreased levels of Ser473 AKT.

\section{Loss of PINK1 leads to cell death and accumulation of ROS}

PINK1 morphants exhibited dark, nontransparent heads as early as $24 \mathrm{hpf}$. Later, at 48 and $72 \mathrm{hpf}$, the heads of MO-injected fish were notably smaller, nontransparent, and occasionally lacking the hindbrain-midbrain boundary. These phenotypes have been attributed to ongoing neurodegeneration (Furutani-Seiki et al.,
$\mathbf{A}$

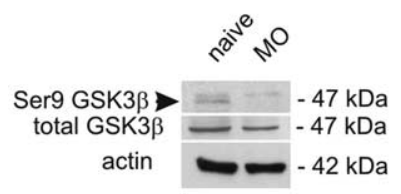

C

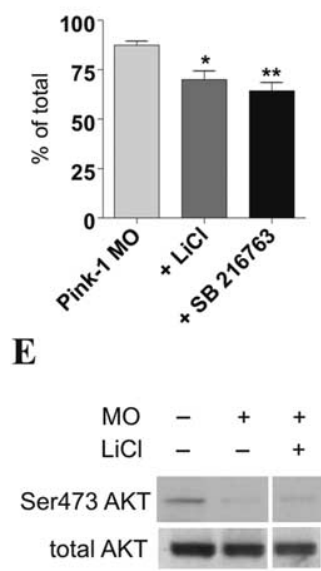

B

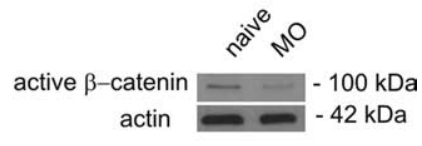

D
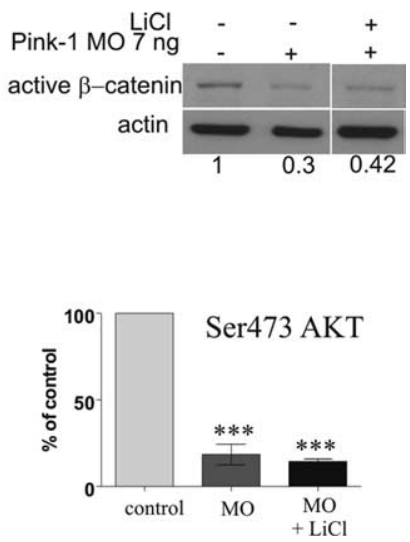

Figure 4. Rescue of PINK1 MO phenotype via modulation of AKT/GSK3 $\beta$ pathway. A, Decrease of Ser9-phosphorylated GSK3 $\beta$ in lysates of 24 hpf PINK1 MO embryos. Because this antibody detects both Ser 9 GSK3 $\beta(47 \mathrm{kDa})$ and GSK3 $\alpha(51 \mathrm{kDa})$, the lower band (GSK3 $\beta$ ) was used for quantification. Blots obtained from three independent experiments were used for quantification and the levels of Ser 9 GSK3 $\beta$ were normalized to the corresponding levels of the total GSK3 $\beta$. Ser9 GSK3 $\beta$ phosphorylation was reduced by the morpholino to $27.6 \%$ ( $\pm 16.56 \%$, SEM) of the control level (set to $100 \%$ ). $p=0.01$ as analyzed by $t$ test. $B$, Decrease of the active form of $\beta$-catenin in $24 \mathrm{hpf}$ embryos injected with $7 \mathrm{ng}$ of PINK1 MO. Active $\beta$-catenin bands were quantified as a function of the actin loading control in three independent experiments. Active $\beta$-catenin levels were reduced by the morpholino to $40.2 \%( \pm 11.1 \%$, SEM) of the control levels (set to 100\%). $p<0.01$ as analyzed by $t$ test. $C$, Rescue of the short tail phenotype in $24 \mathrm{hpf}$ PINK1 MO-injected embryos by nonspecific ( $50 \mathrm{~mm}$ of LiCl) and specific (10 $\mu \mathrm{m}$ of SB216763) GSK3 $\beta$ inhibitors. Bars represent three individual experiments, with 15-20 fish in each group per experiment. ${ }^{*} p<0.05,{ }^{* *} p<0.01$, as analyzed by unconditional logistical regression analysis. $\boldsymbol{D}$, Recovery of active $\beta$-catenin levels in PINK1 M0-injected embryos after treatment with $50 \mathrm{~mm}$ LiCl. The numbers under the blots are the ratios between the active $\beta$-catenin band intensities and actin loading control band intensities in relation to the control values. Independent replicate of the experiment could be seen in Figure $6 C$. E, The activity of AKT is decreased in PINK1 M0-injected embryos at $24 \mathrm{hpf}$. Ser473 AKT bands were quantified as a function of total AKT in three independent experiments. ${ }^{* * *} p<0.01$, as analyzed by $t$ test. Error bars indicate SEM.

1996). Here, the lack of PINK1 protein led to an increase of acridine orange accumulation in the brain and throughout the body at $24 \mathrm{hpf}$ (Fig. 5A). Because acridine orange accumulation in vivo is indicative of the cell death, we examined the activity of caspase-3, which was increased in the whole fish lysates already at $24 \mathrm{hpf}$ (Fig. 5B) above the levels seen in the positive control group (UV-exposed embryos). Exposure to $50 \mathrm{~mm} \mathrm{LiCl}$ for $18 \mathrm{~h}$ led to the partial decrease of caspase- 3 activity in $1 \mathrm{dpf}$ PINK1 MOinjected embryos (Fig. 5C). Administration of the pan-caspase inhibitor zVAD did not rescue the tail phenotype like $\mathrm{LiCl}$ did (data not shown), suggesting that although GSK $3 \beta$ overactivity does contribute to the caspase- 3 activation, the effect of GSK3 $\beta$ inhibitors on the tail phenotype in PINK1 MO is not related to the caspase- 3 activity.

To assess the integrity of the mitochondrial outer membrane, 
A
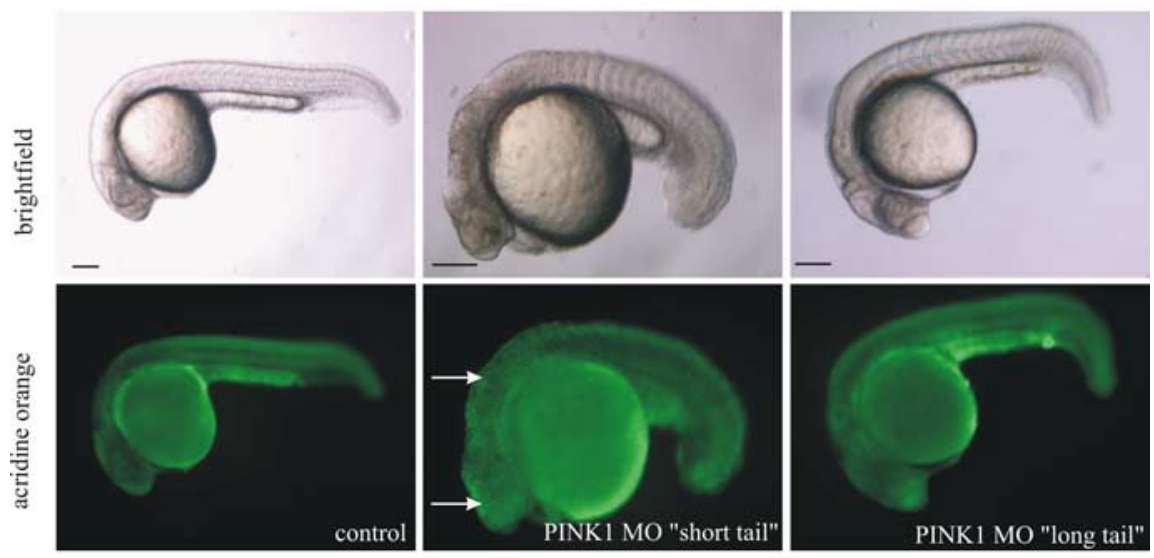

B

C
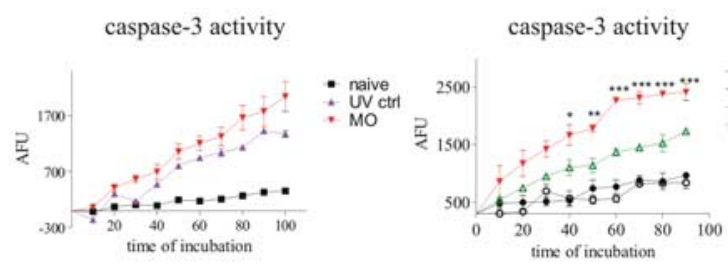

D

JC-1 accumulation

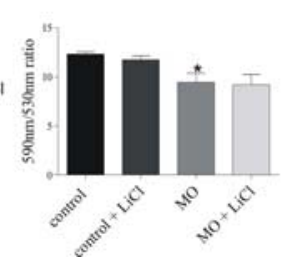

Figure 5. Increase of apoptosis in PINK1 MO-injected fish. A, Acridine orange staining of MO-injected embryos. Stained cells (fluorescent) represent dead cells. The arrows show increased acridine orange accumulation in brain and spine of short-tail PINK1 M0-injected embroys. B, Caspase-3 activity is increased in M0-injected fish at $24 \mathrm{hpf}$. Values represent means of three samples, each of which is the total lysate of 15 fish. $\mathbf{C}, \mathrm{LiCl}(50 \mathrm{~mm})$ rescues the increased levels of caspase- 3 in $24 \mathrm{hpf}$ PINK1 M0-injected embryos. Values represent means of three samples, each of which is the total lysate of 15 fish. ${ }^{*} p<0.05 ;{ }^{* *} p<0.01$; ${ }^{* * *} p<$ 0.01 , as analyzed by one-way ANOVA with Bonferroni post hoc test. $D$, The mitochondrial $\Delta \psi$ membrane potential, represented as the ratio 590/530 nm (orange/green) of JC-1, is decreased in PINK1 morphants. LiCl (50 mm) does not change decreased levels of JC-1 in M0 embryos. Bars represent three independent experiments, each of which uses the total lysate of 80-100 $24 \mathrm{hpf}$ embryos. Scale bars, $100 \mu \mathrm{m}$. Error bars indicate SEM.

mitochondria were isolated from $\sim 100$ embryos at $24 \mathrm{hpf}$ and incubated with JC-1. MO-injected embryos displayed an $\sim 30 \%$ decreased JC-1 orange/green ratio in the mitochondrial fraction, indicating a lower mitochondrial potential $(\Delta \psi)$ (Fig. 5D). Inhibition of GSK3 $\beta$ with LiCl did not improve mitochondrial potential in PINK1 MO embryos. PINK1 morphants also had increased levels of ROS: 24 hpf MO-injected embryos had increased levels of ROS, as detected by accumulation of oxidized CM$\mathrm{H}_{2}$ DCFDA probe in vivo (Fig. $6 \mathrm{~A}$ ). Intracellular oxidation of CM- $\mathrm{H}_{2}$ DCFDA can be caused by various reactive species, including $\mathrm{H}_{2} \mathrm{O}_{2}$, peroxy products, peroxyl radicals, and singlet oxygen. The increased ROS levels caused by the PINK1 MO were mostly normalized by $50 \mathrm{mM} \mathrm{LiCl}$ or antioxidant drugs $(100 \mu \mathrm{M}$ of either GSH or NAC) (Fig. 6A). In addition, these antioxidant drugs resulted in a small improvement in the tail phenotype (Fig. $6 B$ ), and the treated fish looked generally less severely affected by the loss of PINK1. As expected, $\mathrm{LiCl}$ rescued the decrease in active catenin levels in the PINK1 MO-treated fish, whereas GSH and NAC did not (Fig. 6C).

\section{Discussion}

Here, we describe a vertebrate model of PINK1 insufficiency. Decreased PINK1 activity in embryonic zebrafish resulted in a general developmental delay, aggravated by a severe mispatterning of axonal scaffolds and reduction of neuronal populations, in the dopaminergic system but also in other areas (e.g., spinal mo-

tor neurons). We observed a relatively modest decrease of TH-positive cells in the brains of 2 dpf PINK1 MO-injected embryos, $\sim 30 \%$ from the control. It is difficult to assess whether this decrease is attributable to the developmental retardation of dopaminergic neurons, or to the degeneration of already developed neurons. However, neurodegeneration and increased apoptosis (as judged by acridine orange staining and elevated caspase- 3 activity) does occur as a result of PINK1 knockdown, and it is thus likely that this contributes significantly, at least in part, to the neuronal loss observed.

We found that PINK1 knockdown was associated with elevation of GSK3 $\beta$ activity, which contributes to at least some aspects of the knockdown phenotype, because a degree of rescue was seen with GSK $3 \beta$ inhibitors. Our data are compatible with the elevation of GSK3 $\beta$ activity attributable to the inhibition of AKT via dephosphorylation at Ser9. AKT is one of main contributors to the phosphorylation of GSK on Ser9, producing the inhibition of the enzyme.

The question remains how the loss of function of mitochondrially located PINK1 would affect the functional activity of cytoplasmic proteins, such as GSK $3 \beta$ and AKT, and further studies will be required to elucidate the molecular events linking PINK1 to AKT/GSK3 $\beta$. However, GSK3 $\beta$ has been identified within mitochondria (Hoshi et al., 1996), as well as in the cytoplasm. Because the $\mathrm{LiCl}$ rescue is restricted to the tail/trunk organization and development, it is possible that the apparently pleiotropic phenotypes seen in the PINK1 knock-out fish are related to mitochondrial GSK $3 \beta$ and general mitochondrial dysfunction. For instance, zebrafish morphants with specific inner mitochondria membrane pathologies display severe tail/trunk anomalies that are similar to those we saw with PINK1 knock-out (Guo et al., 2004), and PINK1 RNA is enriched in mitochondria rich tissues such as muscles and brain (Unoki and Nakamura, 2001). The roles of PINK1 in mitochondria that have been elucidated to date are compatible with the pleiotropic phenotype model we proposed. Recently, it was shown that the activation of $\mathrm{HtrA} 2 / \mathrm{Omi}$ and consequent protection of mitochondria from stress is PINK1-dependent (Plun-Favreau et al., 2007). In addition, TRAP1 and parkin have been shown to operate downstream of PINK1 (Clark et al., 2006; Park et al., 2006; Pridgeon et al., 2007). All of these proteins are involved in the protection of the cell from various insults, further strengthening the idea of PINK1 being the important neuroprotective mitochondrial protein.

We detected two PINK1-immunopositive bands in the lysates of whole zebrafish embryos. The intensity of both bands was decreased after MO injection and increased after overexpression of wild-type human PINK1 mRNA, supporting the specificity of the observed signals. Whereas the full-length zebrafish PINK1 has predicted molecular mass of $64 \mathrm{kDa}$ and is most likely represented by the bigger band in our experiments, the nature of the 
$\mathbf{A}$

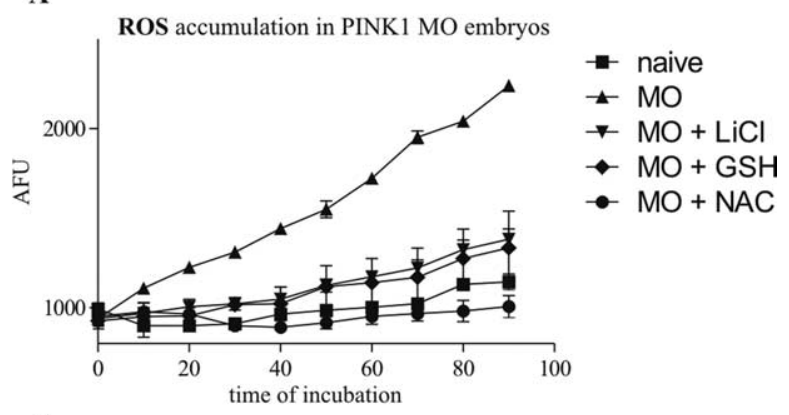

B

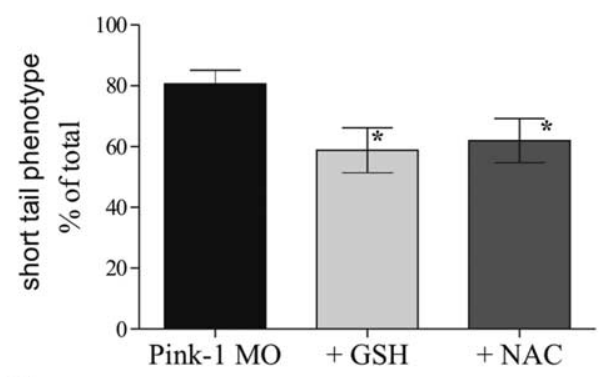

C

$\begin{array}{lllllllll}\mathrm{NAC} & - & - & - & - & - & - & + & + \\ \mathrm{GSH} & - & - & - & - & + & + & - & - \\ \mathrm{LiCl} & - & - & + & + & - & - & - & - \\ \mathrm{MO} & - & + & - & + & - & + & - & +\end{array}$

active catenin
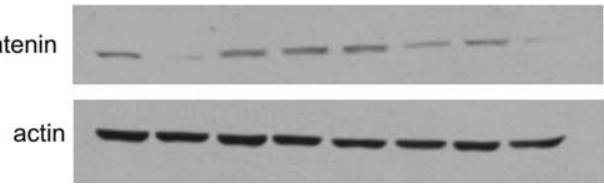

Figure 6. ROS levels are increased in PINK1 MO-injected fish. A, Accumulation of the CM$\mathrm{H}_{2}$ DCFDA dye, as the indicator of ROS levels, in live 24 hpf PINK1 M0-injected embryos. The

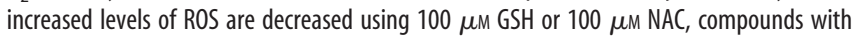
antioxidant qualities. Values represent means of three samples, each of which is the total lysate of 15 fish. $\boldsymbol{B}$, Quantification of the short-tail phenotype at $24 \mathrm{hpf}$ in embryos from $\boldsymbol{A}$ representing three independent experiments, each of which is the quantification of 15-20 $24 \mathrm{hpf}$ embryos. ${ }^{*} p<0.05$, one-tailed $t$ test. Error bars indicate SEM. C, Detection of active catenin in PINK1 $\mathrm{M} 0$-injected fish, treated with $50 \mathrm{~mm} \mathrm{LiCl}, 100 \mu \mathrm{M} \mathrm{GSH}$, and $100 \mu \mathrm{m} \mathrm{NAC.} \mathrm{Gel} \mathrm{is} \mathrm{representative}$ of data from two independent experiments.

smaller band $(\sim 30 \mathrm{kDa})$ is not clear. The truncation of $\mathrm{N}$ terminus of the protein could contribute to the generation of such a fragment (as our antibodies detect $C$ terminus of the protein). Also, in experiments in which films had long exposures, we observed another band (e.g., $50 \mathrm{kDa}$ ) (supplemental Fig. 5A, available at www.jneurosci.org as supplemental material), which could represent another splice variant. This sized PINK1 band has been described in the human brain (Gandhi et al., 2006)

Consistent with loss of PINK1 causing increased GSK3 $\beta$ activity, we observed an increase in the expression of fezl (a gene regulated by the wnt/GSK3 $\beta$ pathway) (Hashimoto et al., 2000b) and its downstream target neurogenin-1 in our PINK1 morphants. Our PINK1 morphants had decreased numbers of dopaminergic neurons, whereas neurogenin-1 overexpression in otherwise normal zebrafish leads to an increase in this neuronal population (Jeong et al., 2006). Thus, it is likely that the phenotype mediated by GSK $3 \beta$ activity in the brain is independent of neurogenin-1 and is mediated by other pathways regulated by this broad-acting enzyme. We observed no obvious benefit of $\mathrm{LiCl}$ treatment on the neurodegeneration in the brain of mor- phants, in contrast to the rescue seen with the tail/trunk phenotype. These findings raise the possibility that PINK1 deficiency may selectively affect mitochondrial function and consequently, the development of mitochondria-rich tissues.

We observed that zebrafish PINK1 morphants had increased levels of ROS as early as at $24 \mathrm{hpf}$. This could be caused by mitochondrial malfunction, as the mitochondrial membrane potential, assessed by accumulation of JC-1, was decreased in PINK1 morphants. However, we cannot exclude the possibility that increased ROS levels result from activation of cell death pathways in these fish. We have attempted to test whether the GSK3 $\beta$ and ROS pathology seen in the PINK1 morphants were related. The antioxidants used did not affect GSK3 $\beta$ activity. However, $\mathrm{LiCl}$ did reduce ROS and caspase- 3 levels while not affecting the decrease of mitochondrial membrane potential, suggesting that at least some of the ROS accumulation may be downstream of GSK $3 \beta$ in this model. Furthermore, LiCl failed to rescue the $\mathrm{TH}+$ neuronal deficit in our morphants (data not shown). This suggests that GSK $3 \beta$ overactivity is related to PINK1 function in peripheral tissues, and the decrease in $\mathrm{TH}+$ neurons is primarily attributable to factors distinct from GSK3 $\beta$.

In our study, we obtained similar rescue of the PINK1 knockdown phenotype with a "specific" GSK3 $\beta$ inhibitor or with lithium, which inhibits this enzyme but also has other effects. Although it is very likely that the effects we observed are caused by GSK3 $\beta$ inhibition, they are probably not caused by a complete inhibition of enzyme activity. The inhibition of GSK $3 \alpha$ and $\beta$ activity results in severe apoptosis in the CNS, accompanied with abnormalities in body axis formation and heart development (Lee et al., 2007). These data indicate that the complete inhibition of this enzyme results in very severe consequences. [It would not really be informative to try to test whether Akt overexpression had similar effects to lithium, as Akt has protective effects independent of GSK3 $\beta$ signaling and has diverse signaling consequences (in addition to GSK3).]

The reduction of PINK1 levels in zebrafish also led to a decreased expression of parkin (Fig. $2 F$ ). In future studies it will be interesting to test whether overexpression of parkin can rescue aspects of the PINK1 knockdown phenotype in a similar way to what was described previously in Drosophila (Clark et al., 2006; Park et al., 2006; Yang et al., 2006). However, such studies will be a major undertaking, as the expression patterns of zebrafish parkin are uncharacterized, and as it is not clear whether zebrafish parkin is functionally ortholgous to human parkin, knockdown and overexpression experiments will be required for robust interpretations.

In conclusion, decreasing levels of PINK1 protein produces significant developmental and neurochemical alterations in embryonic zebrafish. These alterations are clearly associated with mitochondrial alteration, leading to the activation of caspases and accumulation of ROS and with activation of GSK3 $\beta$. These data lead to insights into normal PINK1 function, which is believed to be lost in PD cases with mutations in this gene (Sim et al., 2006). Our data raise the speculative possibility that drugs like lithium chloride and more specific GSK3 $\beta$ inhibitors, as well as antioxidants, may be of value in some forms of $\mathrm{PD}$, particularly in familial cases caused by PINK1 mutations.

\section{References}

Abdelilah S, Mountcastle-Shah E, Harvey M, Solnica-Krezel L, Schier AF, Stemple DL, Malicki J, Neuhauss SC, Zwartkruis F, Stainier DY, Rangini Z, Driever W (1996) Mutations affecting neural survival in the zebrafish Danio rerio. Development 123:217-227. 
Blader P, Fischer N, Gradwohl G, Guillemot F, Strähle U (1997) The activity of neurogenin 1 is controlled by local cues in the zebrafish embryo. Development 124:4557-4569.

Carmichael J, Sugars KL, Bao YP, Rubinsztein DC (2002) Glycogen synthase kinase-3beta inhibitors prevent cellular polyglutamine toxicity caused by the Huntington's disease mutation. J Biol Chem 277:33791-33798.

Castelo-Branco G, Rawal N, Arenas E (2004) GSK-3beta inhibition/betacatenin stabilization in ventral midbrain precursors increases differentiation into dopamine neurons. J Cell Sci 117:5731-5737.

Clark IE, Dodson MW, Jiang C, Cao JH, Huh JR, Seol JH, Yoo SJ, Hay BA, Guo M (2006) Drosophila pink1 is required for mitochondrial function and interacts genetically with parkin. Nature 441:1162-1166.

Claros MG, Vincens P (1996) Computational method to predict mitochondrially imported proteins and their targeting sequences. Eur J Biochem 241:779-786.

Costagli A, Kapsimali M, Wilson SW, Mione M (2002) Conserved and divergent patterns of Reelin expression in the zebrafish central nervous system. J Comp Neurol 450:73-93.

Devine CA, Key B (2003) Identifying axon guidance defects in the embryonic zebrafish brain. Methods Cell Sci 25:33-37.

Furutani-Seiki M, Jiang YJ, Brand M, Heisenberg CP, Houart C, Beuchle D, van Eeden FJ, Granato M, Haffter P, Hammerschmidt M, Kane DA, Kelsh RN, Mullins MC, Odenthal J, Nüsslein-Volhard C (1996) Neural degeneration mutants in the zebrafish, Danio rerio. Development 123:229-239.

Gandhi S, Muqit MM, Stanyer L, Healy DG, Abou-Sleiman PM, Hargreaves I, Heales S, Ganguly M, Parsons L, Lees AJ, Latchman DS, Holton JL, Wood NW, Revesz T (2006) PINK1 protein in normal human brain and Parkinson's disease. Brain 129:1720-1731.

Guo Y, Cheong N, Zhang Z, De Rose R, Deng Y, Farber SA, FernandesAlnemri T, Alnemri ES (2004) Tim50, a component of the mitochondrial translocator, regulates mitochondrial integrity and cell death. J Biol Chem 279:24813-24825.

Hashimoto H, Itoh M, Yamanaka Y, Yamashita S, Shimizu T, Solnica-Krezel L, Hibi M, Hirano T (2000a) Zebrafish Dkk1 functions in forebrain specification and axial mesendoderm formation. Dev Biol 217:138-152.

Hashimoto H, Yabe T, Hirata T, Shimizu T, Bae Y, Yamanaka Y, Hirano T, Hibi M (2000b) Expression of the zinc finger gene fez-like in zebrafish forebrain. Mech Dev 97:191-195.

Healy DG, Abou-Sleiman PM, Casas JP, Ahmadi KR, Lynch T, Gandhi S, Muqit MM, Foltynie T, Barker R, Bhatia KP, Quinn NP, Lees AJ, Gibson JM, Holton JL, Revesz T, Goldstein DB, Wood NW (2006) UCHL-1 is not a Parkinson's disease susceptibility gene. Ann Neurol 59:627-633.

Hoshi M, Takashima A, Noguchi K, Murayama M, Sato M, Kondo S, Saitoh Y, Ishiguro K, Hoshino T, Imahori K (1996) Regulation of mitochondrial pyruvate dehydrogenase activity by tau protein kinase I/glycogen synthase kinase 3beta in brain. Proc Natl Acad Sci U S A 93:2719-2723.

Jeong JY, Einhorn Z, Mercurio S, Lee S, Lau B, Mione M, Wilson SW, Guo S (2006) Neurogenin 1 is a determinant of zebrafish basal forebrain dopaminergic neurons and is regulated by the conserved zinc finger protein Tof/Fezl. Proc Natl Acad Sci U S A 103:5143-5148.

Jowett T, Lettice L (1994) Whole-mount in situ hybridizations on zebrafish embryos using a mixture of digoxigenin- and fluorescein-labelled probes. Trends Genet 10:73-74.

Kaslin J, Panula P (2001) Comparative anatomy of the histaminergic and other aminergic systems in zebrafish (Danio rerio). J Comp Neurol 440:342-377.

Kimmel CB, Ballard WW, Kimmel SR, Ullmann B, Schilling TF (1995) Stages of embryonic development of the zebrafish. Dev Dyn 203:253-310.

Klein C, Schlossmacher MG (2006) The genetics of Parkinson disease: Implications for neurological care. Nat Clin Pract Neurol 2:136-146.
Lee HC, Tsai JN, Liao PY, Tsai WY, Lin KY, Chuang CC, Sun CK, Chang WC, Tsai HJ (2007) Glycogen synthase kinase 3 alpha and 3 beta have distinct functions during cardiogenesis of zebrafish embryo. BMC Dev Biol 7:93.

Levkowitz G, Zeller J, Sirotkin HI, French D, Schilbach S, Hashimoto H, Hibi M, Talbot WS, Rosenthal A (2003) Zinc finger protein too few controls the development of monoaminergic neurons. Nat Neurosci 6:28-33.

Li Y, Tomiyama H, Sato K, Hatano Y, Yoshino H, Atsumi M, Kitaguchi M, Sasaki S, Kawaguchi S, Miyajima H, Toda T, Mizuno Y, Hattori N (2005) Clinicogenetic study of PINK1 mutations in autosomal recessive earlyonset parkinsonism. Neurology 64:1955-1957.

Lin W, Kan UJ (2008) Characterization of PINK1 processing, stability, and subcellular localization. J Neurochem 106:464-474.

Park J, Lee SB, Lee S, Kim Y, Song S, Kim S, Bae E, Kim J, Shong M, Kim JM, Chung J (2006) Mitochondrial dysfunction in Drosophila PINK1 mutants is complemented by parkin. Nature 441:1157-1161.

Plun-Favreau H, Klupsch K, Moisoi N, Gandhi S, Kjaer S, Frith D, Harvey K, Deas E, Harvey RJ, McDonald N, Wood NW, Martins LM, Downward J (2007) The mitochondrial protease HtrA2 is regulated by Parkinson's disease-associated kinase PINK1. Nat Cell Biol 9:1243-1252.

Pridgeon JW, Olzmann JA, Chin LS, Li L (2007) PINK1 Protects against oxidative stress by phosphorylating mitochondrial chaperone TRAP1. PLoS Biol 5:e172.

Rauch GJ, Hammerschmidt M, Blader P, Schauerte HE, Strähle U, Ingham PW, McMahon AP, Haffter P (1997) Wnt5 is required for tail formation in the zebrafish embryo. Cold Spring Harb Symp Quant Biol 62:227-234.

Silvestri L, Caputo V, Bellacchio E, Atorino L, Dallapiccola B, Valente EM, Casari G (2005) Mitochondrial import and enzymatic activity of PINK1 mutants associated to recessive parkinsonism. Hum Mol Genet 14:3477-3492.

Sim CH, Lio DS, Mok SS, Masters CL, Hill AF, Culvenor JG, Cheng HC (2006) C-terminal truncation and Parkinson's disease-associated mutations down-regulate the protein serine/threonine kinase activity of PTEN-induced kinase-1. Hum Mol Genet 15:3251-3262.

Sumanas S, Larson JD (2002) Morpholino phosphorodiamidate oligonucleotides in zebrafish: a recipe for functional genomics? Brief Funct Genomic Proteomic 1:239-256.

Unoki M, Nakamura Y (2001) Growth-suppressive effects of BPOZ and EGR2, two genes involved in the PTEN signaling pathway. Oncogene 20:4457-4465.

Valente EM, Abou-Sleiman PM, Caputo V, Muqit MM, Harvey K, Gispert S, Ali Z, Del Turco D, Bentivoglio AR, Healy DG, Albanese A, Nussbaum R, González-Maldonado R, Deller T, Salvi S, Cortelli P, Gilks WP, Latchman DS, Harvey RJ, Dallapiccola B, et al. (2004) Hereditary early-onset Parkinson's disease caused by mutations in PINK1. Science 304:1158-1160.

Westerfield M (2000) The zebrafish book: a guide for the laboratory use of zebrafish (Danio rerio). Eugene, OR: University of Oregon.

Wyttenbach A, Swartz J, Kita H, Thykjaer T, Carmichael J, Bradley J, Brown R, Maxwell M, Schapira A, Orntoft TF, Kato K, Rubinsztein DC (2001) Polyglutamine expansions cause decreased CRE-mediated transcription and early gene expression changes prior to cell death in an inducible cell model of Huntington's disease. Hum Mol Genet 10:1829-1845.

Wyttenbach A, Sauvageot O, Carmichael J, Diaz-Latoud C, Arrigo AP, Rubinsztein DC (2002) Heat shock protein 27 prevents cellular polyglutamine toxicity and suppresses the increase of reactive oxygen species caused by huntingtin. Hum Mol Genet 11:1137-1151.

Yang Y, Gehrke S, Imai Y, Huang Z, Ouyang Y, Wang JW, Yang L, Beal MF, Vogel H, Lu B (2006) Mitochondrial pathology and muscle and dopaminergic neuron degeneration caused by inactivation of Drosophila Pink1 is rescued by Parkin. Proc Natl Acad Sci U S A 103:10793-10798. 